\title{
Hepatic Sinusoidal Obstruction Syndrome in the Era of Defibrotide
}

Ozkan MC', Sahin $\mathrm{F}^{2}$, Besisik $\mathrm{SK}^{3}$ and Saydam $\mathrm{G}^{2 *}$ ${ }^{1}$ Department of Hematology, Inonu University Medical School, Turkey

${ }^{2}$ Department of Hematology, Ege University Medical

School, Turkey

${ }^{3}$ Department of Hematology, Istanbul University, Turkey

*Correspondling author: Guray Saydam, Department of Hematology, Ege University Medical School, Turkey

Received: December 18, 2016; Accepted: February 06, 2017; Published: February 09, 2017

\begin{abstract}
Background: Hepatic sinusoidal obstruction syndrome (SOS) termed as hepatic veno-oclusive disease previously (VOD), is a toxic injury of liver sinusoids resulting obliterative venulitis of the terminal hepatic venules. In hematopoietic stem cell transplantation (HSCT) setting, SOS appears at a rate of 10 to $60 \%$ and severe SOS with hepatic failure causes considerable mortality.

Case Report: A 40-year-old male with myelodysplastic syndrome was underwent HSCT from matched unreleated donor in active disease status. Hepatic SOS was diagnosed on 21th day of HSCT with epigastric pain and abdominal distension. The patient was successfully treated with defibrotide and steroids.

Conclusion: Defibrotide, a novel agent in SOS, has been shown to improve the clinical outcome and survival in patients with severe VOD. Avoiding from major risk factors is primary method of preventing from SOS. Patients identified as being at higher risk for SOS and the risk could not be decreased, should be considered for DF prophylaxis.
\end{abstract}

Keywords: Defibrotide; Sinusoidal obstruction syndrome; Veno-occlusive disease

\section{Introduction}

Hepatic sinusoidal obstruction syndrome (SOS) is an obliterative venulitis of the terminal hepatic venules, previously termed as hepatic veno-occlusive disease (VOD). The first report as obliterative endophlebitis was attributed to syphilis, whereas many years later it was reported in Jamaican drinkers of bush tea $[1,2]$. Currently, SOS is encountered mainly as a result of cytoreductive therapy prior to hematopoietic stem cell transplantation (HSCT), following oxaliplatin-containing adjuvant or neoadjuvant chemotherapy for colorectal carcinoma metastatic to the liver and treated by partial hepatectomy, in patients taking pyrrolizidine alkaloidcontaining herbal remedies, and in other particular settings such as liver transplantation, high dose radiation therapy to the liver (usually exceeding $30 \mathrm{~Gy}$ ) without cytoreductive chemotherapy, and radioembolization of liver tumors [3-8].

Hepatic SOS may occur at any age. Toxic injury to liver sinusoids causes sloughing of endothelial cells which embolise to hepatic venules and cause eventual fibrosis of the venules. This results in hepatic congestion and post sinusoidal portal hypertension [9]. The incidence of hepatic SOS ranges from 3 to $54 \%$ in the largest series which are published mostly before some prophylactic measures where the disease was documented as a potentially life-threatening complication observed after HSCT [10].

\section{Case Presentation}

A 40-year-old male with myelodysplastic syndrome (MDS) as classified refractory anemia with excess blasts type II received induction chemotherapy with standard doses of idarubicin and cytarabine, followed by consolidation treatment with high dose cytarabine. While he has proved to be not having a matched unrelated donor (MUD), intensificated chemotherapy was with autologous HSCT. The patient had a relapse after 15 months and was treated by reinduction with azacytidine of five cycles and refereed to Bone Marrow Transplant Center. He underwent HSCT from MUD in active disease status as MDS RAEB-II. The conditioning regimen was busulfan and cyclophosphamide in standard doses with defibrotide (DF) prophylaxis at a dose $25 \mathrm{mg} / \mathrm{kg} /$ day (intravenously every $6 \mathrm{~h}$ in a 2 -h administration) and urso-deoxycolic acid. The patient experienced epigastric pain on 21th days after HSCT. On examination, he had right upper quadrant tenderness and abdominal distension. Bilirubin (direct biluribin; $2.36 \mathrm{mg} / \mathrm{dl}$ ) and gamma glutamyle transferase levels were mild increased, and transaminases were elevated by less than two-fold. Abdominal ultrasound at the time revealed diffuse thickening of the gallbladder wall and sludge and minimal ascite. Hepatic and portal veins were patent on ultrasound. Leucocyte engraftment was established but he was still thrombocytopenic and needed frequent thrombocyte transfusions. Hepatic SOS was diagnosed clinically. The patient was then treated with fluid restriction and sprinolactone. The dose of defibrotide was increased to $40 \mathrm{mg} / \mathrm{kg} /$ day and methylprednisolone was started with a goal maintaining for at least 3 weeks and continue until the patient's symptoms resolve. In 3 days all symptoms/signs were resolved.

\section{Clinical presentation and diagnosis}

Hepatic SOS' diagnosis based mainly on symptoms. Blood test results that suggest liver dysfunction are directing. The HSCT teams in Seattle and Baltimore described two different sets of clinical criteria (Table 1) [11,12]. Both of them preclude late appearing SOS. Ultrasound findings, such as hepatomegaly, ascites, gall bladder wall 
Table 1: Clinical criteria for diagnosis of SOS.

\begin{tabular}{|c|c|c|c|c|}
\hline & Initial Seattle criteria & Modified Seattle criteria & Baltimore criteria & Paediatrician modification \\
\hline Up to day after haematopoietic cell transplantation & +30.day & +20.day & +21.day & +30.day \\
\hline Bilirubin $\geq 2 \mathrm{mg} / \mathrm{dl}$ & $>/=2 \mathrm{mg} / \mathrm{dl}$ & $>/=2 \mathrm{mg} / \mathrm{dl}$ & $>/=2 \mathrm{mg} / \mathrm{dl}$ & $>/=2 \mathrm{mg} / \mathrm{dl}$ \\
\hline Painful hepatomegaly & Yes & Yes & Yes & Yes \\
\hline Weight gain & Yes & $>2 \%$ & $>5 \%$ & $>5 \%$ \\
\hline Ascites & Yes & & Yes & Yes \\
\hline
\end{tabular}

Number criteria: Initial Seattle criteria: $\geq 2$ criteria, Modified Seattle criteria: $\geq 2$ criteria, Baltimore criteria: $\uparrow$ bilirubin level and : $\geq 2$ criteria Paediatrician modification: $\geq 2$ criteria

thickening (>6-8 $\mathrm{mm}$ ) are nonspecific. Doppler ultrasonography suggesting attenuated or reversed hepatic venous flow (portal vein dilatation, portal venous pulsatility, hepatofugal portal venous flow) and elevated hepatic artery resistive index (>0.8), may help in the differential diagnosis $[13,14]$. Occasionally, invasive tests are necessary. These tests include liver biopsy or measurement of blood pressure in the hepatic veins and portal vein (hepatic venous gradient pressure; HVGP) which is measured through the jugular vein. A HVGP $\geq 10 \mathrm{mmHg}$ in a patient without previous liver disease is seen almost exclusively in SOS [15].

Among the established SOS criteria there are some findings which are pointing also to SOS diagnosis. Thrombocytopenia, with a rapid consumption of transfused platelets is frequently observed phenomenon. Renal insufficiency or failure, pleural effusion, pulmonary infiltrates, hypoxia, confusion and encephalopathy can reflect the severity maybe also the irreversibility of the disease [16].

\section{Biological markers}

As noninvasive methods for diagnosing and prognosing SOS, there are some studies to identify candidate biomarkers. Increase in levels of plasminogen activator inhibitor-1 (PAI-1) (marker with the highest specificity and sensitivity for SOS), aminopropeptides of type III collagen, and hyaluronic acid (HA), are thought in general of little utility in routine clinical practice [14]. In a study, it has been shown that. L-Ficolin, HA, and vascular cell adhesion molecule-1 are prognostic biomarkers of SOS before symptoms appear and these biomarkers can stratify patients at risk for SOS as early as the day of HSCT [17].

\section{Pathology of SOS}

SOS may exhibit acute, subacute, and chronic features, depending upon when liver material is obtained. Lesions can be focal [9].

Acute SOS: Striking centrilobular congestion, with centrilobular hepatocellular necrosis and accumulation of hemosiderinladen macrophages are the main findings. The terminal hepatic venules exhibit intimal edema, without obvious fibrin deposition or thrombosis. The cells round up and slough off the sinusoidal wall, embolizing downstream and obstructing sinusoidal blood flow. Erythrocytes leak into the space of Disse and cellular debris downstream accumulate in the terminal hepatic vein which were followed by proliferation of perisinusoidal stellate cells and subendothelial fibroblasts in the terminal hepatic vein.

Subacute SOS (days to weeks): Collagen accumulated in and around the affected terminal hepatic venule which resulted to progressive obliteration of the venule.

Table 2: Grade of SOS.
\begin{tabular}{|c|c|c|c|}
\hline & Mild & Moderate & Severe \\
\hline Bilirubin, mg/dL & $<5$ & $5.1-8$ & $>8$ \\
\hline Liver function & $<3 \times$ normal & $3-8 \times$ normal & $>8 \times$ normal \\
\hline Weight above baseline & $<2 \%$ & $2-5 \%$ & $>5 \%$ \\
\hline Renal function & Normal & $<2 \times$ normal & $>2 \times$ normal \\
\hline Rate of change & Slow & Moderate & Rapid \\
\hline
\end{tabular}

Chronic SOS (weeks to months): Perivenular dense fibrosis radiates out into the parenchyma. The scar tissue contains hemosiderin-laden macrophages, and terminal hepatic vein lumina cannot be identified which terminaed rarely into cirrhosis.

\section{Treatment of established sos}

There is no standard treatment regimen. For deciding on therapy, defining the picture of disease in terms of grading is important (Table 2). In patients with mild grade SOS, "watch and wait" protocol is a recommended management type. On the other hand the disease biology can vary very quickly from moderate to severe or from moderate to mild. For patients with severe SOS defined by a rapid rise in the bilirubin level (e.g., doubling or tripling over 24 hours) and rapid weight gain, treatment should be instituted rapidly $[14,16,18]$.

Supportive care: Adequate fluid and sodium balance for intravascular volume maintenance and renal perfusion with restriction of salt and water intake, and avoidance of hepato- and nephrotoxic drugs are the initial measures. Diuretics could be carefully added if weight-gain progresses despite these basic measures $[9,14,16,18]$.

Analgesia is really requisite management. Frequently narcotic type analgesics can suppress the pain.

Paracentesis, thoracentesis, oxygen therapy are other rarely needed supportive treatments. If needed, ascites removal must be in small daily quantities, to avoid renal flow reduction.

Low dose dopamine, haemodialysis, haemofiltration and mechanical ventilation may also be symptomatic measures.

Anticoagulation: Protein C concentrate is with some beneficial effect. Antithrombin III has also shown efficacy. Recombinant human tissue plasminogen activators (rt-PA $0.05 \mathrm{mg} / \mathrm{kg} / \mathrm{h}$ during 4 hours; maximum $10 \mathrm{mg} /$ day $2-4$ days \pm sodium heparin $20 \mathrm{U} / \mathrm{kg}$ as a bolus (maximum $1000 \mathrm{U}$ ) followed by $150 \mathrm{U} / \mathrm{kg} /$ day by continuous infusion for 10 days) are effective in less $<30 \%$ and with high bleeding risk. rt-PA has been shown to be effective only in patients with a non-advanced SOS. Its use is contraindicated in patients with multi- 
Table 3: Risk factors for sinusoidal obstruction syndrome after HCT.

\begin{tabular}{|c|c|}
\hline Patient related & \\
\hline Age & Younger < older \\
\hline Sex & Male $<$ female \\
\hline Karnofsky Index & $100-90<$ lower than 90 \\
\hline Diagnosis & Non-malignancy <malignancy $<$ some malignancy \\
\hline Status of disease & Remission $<$ relapse \\
\hline AST level before HSCT & Normal < high \\
\hline Previous liver radiation & No $<$ Yes \\
\hline Liver status & Normal < fibrosis, cirrhosis \\
\hline Iron overloa & Absent $<$ present \\
\hline CMV serology & Negative $<$ positive \\
\hline Previous drugs & Gemtuzumab ozogamicine \\
\hline Concomitant drugs & Progestogens, ketoconazole, cyclosporine, tacrolimus, methotrexate, amphotericin B, vancomycin, acyclovir \\
\hline Genetic polymorphisms & GSTM1 or GSTT1, among others \\
\hline \multicolumn{2}{|l|}{ Transplant related } \\
\hline Type of HCT & Syngeneic/autologous < allogeneic \\
\hline Type of donor & HLA identical sibling $<$ unrelated \\
\hline Grade of compatibility & Match $<$ minor-mismatch $<$ majormismatch \\
\hline T-cell in the graf & T-cell depleted $<$ non T-cell depleted \\
\hline \multicolumn{2}{|l|}{ Conditioning regimen } \\
\hline TBI & Fractionated < single dose Low dose-rate < high dose-rate Less than 12 Gy < more than 12 Gy \\
\hline Total dose & Cy alone $<\mathrm{Cy}-\mathrm{TBI}<\mathrm{BVC} \mathrm{RIC}<\mathrm{MAC}$ \\
\hline Busulfan & Intravenous $<$ oral dose targeted $<$ oral non adjusted \\
\hline GvHD prophylaxis & $\mathrm{CNI}<\mathrm{CNI}+$ sirolimus \\
\hline HCT number & First $<$ second HSCT \\
\hline
\end{tabular}

organ dysfunction syndrome (MODS), haemorrhages or severe hypertension [19].

Steroid therapy: Corticosteroids are potent cytokine inhibitors and therefore may have a role in the treatment of SOS. High-dose steroid therapy consisted of intravenous methylprednisolone $500 \mathrm{mg} /$ $\mathrm{m}^{2}$ per dose every 12 hours for six doses, followed by a taper to $2 \mathrm{mg} /$ $\mathrm{kg} /$ day for 3 days, and subsequently tapered per treating physician preference. Recommendations for steroid therapy is initiating at or before first ultrasound evidence of reversal of portal venous flow. Steroid therapy is easily available at any institution with known expected side effects and standard monitoring which make it distingue but further prospective clinical trials are required to assess the true efficacy of high-dose steroid therapy for post-HSCT SOS [20].

Defibrotide therapy: DF is a sodium salt of a complex mixture of single-stranded oligodeoxyribonucleotides derived from porcine mucosa DNA. The probable mechanism of DF action is anti-inflammatory, anti-thrombotic and anti-apoptotic effects on endothelial cells. The efficacy of DF for severe SOS was first demonstrated in a retrospective dose escalation study (doses ranging 5 to $60 \mathrm{mg} / \mathrm{kg}$ ) that include 19 patients. Resolution of SOS was observed in eight patients (42\%), six of whom survived longer than
100 day which was followed by several studies [21,22]. In general, DF provides resolutions of symptoms in nearly half of the patients with the recommended dose $25 \mathrm{mg} / \mathrm{kg} / \mathrm{day}$. It is recommended usually in severe SOS as started immediately whereas delay in starting decreases of complete response rate [23]. DF is well tolerated: $22 \%$ of patients experienced at least one adverse event, which primarily consisted of hemorrhage (17\%) and hypotension (4\%) [24]. In a pediatric patient's study, it was documented that prophylaxis with DF for SOS leads to a delay to the engraftment of polymorphonuclear neutrophils and white blood cells [25].

Duration of DF: DF should be continued at least 3 weeks and until the patient's all symptoms resolved. For patients with severity of less then severe SOS, 14 days of treatment may be sufficient.

Transjugular intrahepatic portosystemic shunt (TIPS): TIPS is the procedure to decompress the portal circulation [26].

Liver transplantation: Patients' who are expected to have a good outcome in the absence of liver disease could be liver transplant candidates [27].

\section{Risk factors, prevention and prophylaxis}

SOS can be with fatal outcome. The primary goal should be to 
identify patients with high risk for SOS development and implement efforts to prevent SOS. The pathophysiology of SOS is related mainly with damage to the hepatic endothelial cells venules [28]. Injured endothelial cells express cytokines such as tumor necrosis factor- $\alpha$, interleukin-6, and endothelin-1 that cause hypercoagulability and inflammatory cell infiltration. VCAM-1, P-selections, and intercellular adhesion molecule 1 (ICAM-1) are other expressing molecules. PAI1 , stimulated by transforming growth factor $\beta$ (TGF- $\beta$ ) which was released from activated platelets, elevates as a marker of endotelial injury $[29,30]$. Endothelial cell injury increase with cytokines and cytokines increase with injury thus creating a vicious cycle toward SOS. Marked depletion of glutathione in subendotelial cells that precedes cell death, decreased nitric oxide levels due to decrease in hepatic flow and increase of matrix metalloproteinase- 9 and 2 are the other factors that participate to this cycle $[31,32]$. Fibrin deposition, clot formation, extravasation of red blood cells and leukocytes into the space of Disse, narrows the sinusoids, causes portal hypertension and reduces the hepatic venous outflow. Liver enlarges with capsular distension which is sensed clinically as right upper qudrant pain.

The incidence of SOS is related to the presence of several risk factors (Table 3). The incidence of SOS after autologous HSCT is $5 \%$ it comes out up to $60 \%$ after allogeneic HSCT [33]. While the increased incidence of SOS in the allogeneic HSCT is associated with alloreactivity and hepatotoxicity of some drugs used in the conditioning regimen [34]. The haemochromatosis C282Y allele was also reported as a genetic predisposition for SOS [33].

Concomitant medications like norethisterone to prevent menstruation and sirolimus alone or in combination with tacrolimus used for graft versus host disease prophylaxis may also be associated with an increased risk of SOS $[34,35]$.

Patients who have liver diseases like acute hepatitis, iron overload, elevated hepatic enzymes could be delayed for transplant. Reduction in the dose of conditioning cytotoxic drugs can be an option for patients with irreversible risk factors.

Ursodeoxycholic acid (ursodiol) beginning two weeks before transplantation is commonly used. That being said, the evidence as to whether early prophylactic use of ursodiol reduces the incidence of SOS in the HSCT population is equivocal. Ursodiol functions to reduce the fraction of potentially hepatotoxic hydrophobic bile acids in the hepatobiliary system. It can also have modulating effects on cytokine expression and reduce inflammation [36,37].

Glutamine supplementation, have been reported as having reduced incidence of SOS [38].

Low-dose heparin prophylaxis is a aggressive approach and requires an infusion regime whereas the evidence for efficacy is equivocal [39]. In the pediatric HSCT population, a prophylactic regime of enoxaparin or ursodiol and vitamin $\mathrm{E}$ has been shown of potential value [40].

The addition of bevacizumab a monoclonal antibody directed against VEGF to oxaliplatin-based chemotherapy can attenuate the incidence and severity of SOS [41].

The study between Jan 25, 2006, and Jan 29, 2009, as phase 3, randomised controlled trial in 180 paediatric HSCT patients, showed that DF prophylaxis seems to reduce incidence of SOS. Patients were randomly allocated to the DF group by 30 days of HSCT. SOS developed of $12 \%$ in DF group compared to $20 \%$ in control group [42].

\section{Conclusion}

Avoiding from major risk factors is primary method of preventing from SOS. Patients identified as being at higher risk for SOS and the risk could not be decreased, should be considered for prophylaxis. Severe SOS should be treated promptly, using the measures described here and with DF. Although this complication can be devastating, the majority of these patients are expected to improve.

\section{References}

1. Hess J. Fatal obliterative endophlebitis of the hepatic vein. Am J Med Sci.1905; 130: 986-1001.

2. Bras G, Jelliffe DB, Stuart KI. Veno-occlusive disease of liver with nonportal type of cirrhosis, occurring in Jamaica. Arch Pathol Lab Med. 1954; 57: 285300.

3. Jacobs P, Miller JL, Uys CJ, Dietrich BE. Fatal veno-occlusive disease of the liver after chemotherapy, whole-body irradiation and bone marrow transplantation for refractory anemia. S Afr Med J. 1979; 55: 5-10.

4. Shibayama Y, Hashimoto K, Nakata K. Focal veno-occlusive lesions following metastasis of cancer in the liver with special reference to obstruction of lymphatics in hepatic veins. Virchows Arch [A]. 1991; 418: 169-174.

5. McLean EK. The toxic actions of pyrrolizidine (Senecio) alkaloids. Pharmaco Rev. 1970; 22: 429-483

6. Sempoux C, Horsmans Y, Geubel A, Fraikin J, Van Beers BE, Gigot JF, et al Severe radiation-induced liver disease following localized radiation therapy for biliopancreatic carcinoma: activation of hepatic stellate cells as an early event. Hepatology. 1997; 26: 128-134.

7. Sebagh M, Debette M, Samuel D, Emile JF, Falissard B, Cailliez V, et al. "Silent" presentation of veno-occlusive disease after liver transplantation as part of the process of cellular rejection with endothelial predilection. Hepatology. 1999; 30: 1144-1150.

8. Sangro B, Gil-Alzugaray B, Rodriguez J, Sola I, Martinez-Cuesta A, Viudez A, et al. Liver disease induced by radioembolization of liver tumors: description and possible risk factors. Cancer. 2008; 112: 1538-1546.

9. Q Fan C, Crawford JM. Sinusoidal Obstruction Syndrome (Hepatic VenoOcclusive Disease). J Clin Exp Hepatol. 2014; 4: 332-346.

10. Carreras E. Veno-occlusive disease of the liver after hemopoietic cell transplantation. Eur J Haematol. 2000; 64: 281-291.

11. McDonald GB, Sharma P, Matthews DE, Shulman HM, Thomas ED. Venoocclusive disease of the liver after bone marrow transplantation: diagnosis, incidence, and predisposing factors. Hepatology. 1984; 4: 116122.

12. Jones RJ, Lee KS, Beschorner WE, Vogel VG, Grochow LB, Braine HG, et al. Venoocclusive disease of the liver following bone marrow transplantation. Transplantation. 1987; 44: 778-783.

13. Dignan FL, Wynn RF, Hadzic N, Karani J, Quaglia A, Pagliuca A, et al. Haemato-oncology Task Force of British Committee for Standards in Haematology, British Society for Blood and Marrow Transplantation. BCSH/ BSBMT guideline: diagnosis and management of veno-occlusive disease (sinusoidal obstruction syndrome) following haematopoietic stem cell transplantation. Br J Haematol. 2013; 163: 444-457.

14. Carreras E. Early complications after HSCT.

15. Carreras E, Grañena A, Navasa M, Bruguera M, Marco V, Sierra J, et al. Transjugular liver biopsy in BMT. Bone Marrow Transplant. 1993; 11: 21-26.

16. Carreras E. How I manage sinusoidal obstruction syndrome after haematopoietic cell transplantation. Br J Haematol. 2015; 168: 481-491. 
17. Akil A, Zhang Q, Mumaw CL, Raiker CL, Yu J, Velez de Mendizabal N, et al. Biomarkers for Diagnosis and Prognosis of Sinusoidal Obstruction Syndrome after Hematopoietic Cell Transplantation. Biol Blood Marrow Transplant. 2015; 10: 1739-1745.

18. Chao N. How I treat sinusoidal obstruction syndrome. Blood. 2014; 123: 4023-4026.

19. Bearman SI, Lee JL, Baron AE, McDonal GB. Treatment of hepatic venocclusive disease with recombinant human tissue plasminogen activator and heparin in 42 marrow transplant patients. Blood. 1997; 89: 1501-1506.

20. Myers KC, Lawrence J, Marsh RA, Davies SM, Jodele S. High-dose methylprednisolone for veno-occlusive disease of the liver in pediatric hematopoietic stem cell transplantation recipients. Biol Blood Marrow Transplant. 2013; 19: 500-503.

21. Richardson PG, Elias AD, Krishnan A, Wheeler C, Nath R, Hoppensteadt $D$, et al. Treatment of severe venoocclusive disease with defibrotide: compassionate use results in response without significant toxicity in a highrisk population. Blood. 1998; 92: 737- 744

22. Kalayoglu-Besisik S, Yenerel MN, Calıskan Y, Ozturk S, Besisik F, Sargin D. Time-related changes in the incidence, severity, and clinical outcome of hepatic veno-occlusive disease in hematopoietic stem cell transplantation patients during the past 10 years. Transplant Proc. 2005; 37: 2285-2289.

23. Corbacioglu S, Greil J, Peters C, Wulffraat N, Laws HJ, Dilloo D, et al. Defibrotide in the treatment of children with veno-occlusive disease (VOD): a retrospective multicentre study demonstrates therapeutic efficacy upon early intervention. Bone Marrow Transplant. 2004; 33, 189-919.

24. Richardson PG, Smith AR, Triplett BM, Kernan NA, Grupp SA, Arai S, et al. Results of the large prospective study on the use of defibrotide (DF) in the treatment of hepatic veno-occlusive disease (VOD) in hematopoietic stem cell transplant (HSCT). Early intervention improves outcome - updated results of a treatment IND (T-IND) expanded access protocol. ASH Annual Meeting Abstracts. 2013; 122: 700-701.

25. Maximova N, Pizzol A, Giurici N, Granzatto M. Does defibrotide induce a delay to polymorphonuclear neutrophil engraftment after hematopoietic stem cell transplantation? Observation in a pediatric population. Adv Ther. 2015; 32: 381-386

26. Rajvanshi P, McDonald GB. Expanding the use of transjugular intrahepatic portosystemic shunts for veno-occlu- sive disease. Liver Transpl. 2001; 7 : 154-159

27. Mellgren K, Fasth A, Saalman R, Olausson M, Abrahamsson J. Liver transplantation after stem cell transplantation with the same living donor in a monozygotic twin with acute myeloid leukemia. Ann Hematol. 2005; 84: 755-757.

28. Shulman, HM, Gown AM, Nugent DJ. Pihusch V, Pihusch M, Penovici M et al. Transforming growth factor beta-1 released from platelets contributes to hypercoagulability in veno-occlusive disease following hematopoetic stem cell transplantation. Thromb Res. 2005; 116: 233- 240.

29. Pihusch V, Pihusch M, Penovici M, Kolb HJ, Hiller E, Pihusch R. Transforming growth factor beta-1 released from platelets contributes to hypercoagulability in veno-occlusive disease following hematopoetic stem cell transplantation. Thromb Res. 2005; 116: 233- 240.
30. Qi K, Li H, An L, Song G, Pan B, Chen W, et al. The Correlation Between Platelet Activation and Liver Injury by Conditioning and Bone Marrow Transplantation. Transplant Proc. 2014; 46: 1523- 1530.

31. Helmy A. Review article: updates in the pathogenesis and therapy of hepatic sinusoidal obstruction syndrome. Aliment Pharmacol Ther. 2006; 23: 11- 25

32. Carreras E, Diaz-Beya M, Rosinol L, Martinez C, Fernandez-Aviles F, Rovira M. The Incidence of Veno-Occlusive Disease Following Allogeneic Hematopoietic Stem Cell Transplantation Has Diminished and the Outcome Improved over the Last Decade. Biol Blood Marrow Transplant. 2011; 17 : 1698-1720.

33. Kallianpur AR, Hall LD, Yadav M, Byrne DW, Speroff T, Dittus RS, et al. The hemochromatosis $\mathrm{C} 282 \mathrm{Y}$ allele: a risk factor for hepatic venoocclusive disease after hematopoietic stem cell transplantation. Bone Marrow Transplant. 2005; 35: 1155- 1164.

34. Hagglund $H$, Remberger M, Klaesson S, Lonnqvist $B$, Ljungman $P$, Ringden O. Norethisterone treatment, a major riskfactor for veno-occlusive disease in the liver after allogeneic bone marrow transplantation. Blood. 1998; 92: 4568- 4572.

35. Cutler C, Stevenson K, Kim HT, Richardson P, Ho VT, Linden E, et al. Sirolimus is associated with veno-occlusive disease of the liver after myeloablative allogeneic stem cell transplantation. Blood 2008; 112: 44254433.

36. Ruutu T, Eriksson B, Remes K, Juvonen E, Volin L, Remberger M, et al Ursodeoxycholic acid for the prevention of hepatic complications in allogeneic stem transplantation. Blood. 2002; 100: 1977-1983.

37. Yoshikawa M, Tsujii T, Matsumura K, Yamao J, Matsumura Y, Kubo R, et al. Immunomodulatory effects of ursodeoxycholic acid on immune responses. Hepatology. 1992; 16: 358-364.

38. Brown SA, Goringe A, Fegan C, Davies SV, Giddings J, Whittaker JA, et al. Parenteral glutamine protects hepatic function during bone marrow transplantation. Bone Marrow Transplant. 1998; 22: 281-284.

39. Attal M, Huguet F, Rubie H, Huynh A, Charlet JP, Payen JL, et al. Prevention of hepatic veno-occlusive disease after bone marrow transplantation by continuous infusion of low-dose heparin: a prospective, randomized trial. Blood. 1992; 79: 2834-2840.

40. Gökce M, Kuskonmaz B, Cetin M, Uckan Cetinkaya D, Tuncer M. Coexisting or underlying risk factors of hepatic veno-occlusive disease in pediatric hematopoietic stem cell transplant recipients receiving prophylaxis. Exp Clin Transpl. 2013; 11: 440-446.

41. Rubbia-Brandt L, Lauwers GY, Wang H, Majno PE, Tanabe K, Zhu AX, et al. Sinusoidal obstruction syndrome and nodular regenerative hyperplasia are frequent oxaliplatin-associated liver lesions and partially prevented by bevacizumab in patients with hepatic colorectal metastasis. Histopathology. 2010; 56: 430-439

42. Corbacioglu S, Cesaro S, Faraci M, Valteau Couanet D, Gruhn B, Rovell A, et al. Defibrotide for prophylaxis of hepatic veno-occlusive disease in paediatric haemopoietic stem-cell transplantation: an open-label, phase 3 , randomised controlled trial. Lancet. 2012; 379: 1301-1309.
Ann Hematol Oncol - Volume 4 Issue 1 - 2017

ISSN : 2375-7965 | www.austinpublishing group.com

Saydam et al. (C) All rights are reserved
Citation: Ozkan MC, Sahin F, Besisik SK and Saydam G. Hepatic Sinusoidal Obstruction Syndrome in the Era of Defibrotide. Ann Hematol Oncol. 2017; 4(1): 1131. 